\title{
Frontiers in Surgical Evolution: A Festschrift Honoring Ernst Klar
}

\author{
Guido Alsfasser \\ Department of General, Thoracic, Vascular and Transplantation Surgery, University of Rostock, Rostock, Germany
}

This issue of VisCERAL MEDICINE is dedicated to Professor Dr. Ernst Klar, FACS, Chairman of the Department of General, Thoracic, Vascular and Transplantation Surgery, University of Rostock, Germany. On 21 September, 2018, his former fellows, teachers, friends and trainees came together to celebrate his academic and professional career. We created a Festschrift which includes various presentations of this symposium. A variety of themed presentations focused on both Professor Klar's academic and professional life. He has been an extremely diverse surgeon and was amongst one of the first German surgeons to perform a thyroidectomy for thyroid cancer in children. His basic research in the field of acute pancreatitis is one of the few basic science studies that has greatly impacted clinical practice in the treatment of this disease in humans. Another focus of his work has been surgical therapies in pancreatic disease, making him a wholly dedicated pancreatic surgeon. Furthermore, an important emphasis in his surgical life has been drawn to the surgical treatment of chronic inflammatory bowel disease and he has become and remains a renowned expert in this field. Last but not least, Professor Klar has performed a significant number of liver transplants as well as promoting an enormous amount of research in this particular field. He has always initiated discussions concerning organ quality and their allocation which continues even today to be a somewhat challenging topic.

In this issue of VISCERAL MEDICINE we are therefore proud to present the following articles: Garg et al. [1] answer the challenging question whether hyperthermic intrapertioneal chemotherapy still plays a role despite promising results of modern systemic chemotherapies. Weber [2] explains why medullary thyroid carcinoma needs considerable experience in state-of-the-art treatment. In separate chapters on Crohn's disease and ulcerative colitis, Kienle [3] as well as Kuehn and Hodin [4] discuss the effect of chemotherapeutic agents on the incidence and need of surgical treatment in chronic inflammatory bowel disease. Alberts and Alsfasser [5] demonstrate how conservative treatment of severe acute pancreatitis can be without negative effects on long-term survival. D'Haese and Werner [6] provide an interesting overview about research studies that really influenced clinical therapy in acute pancreatitis. Bausch and Keck [7] present the state of the art in minimally invasive surgery in pancreatic disease. And last but by no means least, Kahn and Schemmer [8] give an overview of the possibilities of improving organ quality in liver transplants while Otto [9] discusses a possible impact of donor shortage on short- and long-term results in liver transplantation.

This focus issue on 'Frontiers in Surgical Evolution' most certainly covers a variety of interesting topics and I thank each and every author for their invaluable contribution.

\section{Disclosure Statement}

The author has no conflicts of interest to declare.

\section{References}

1 Garg PK, Brandl A, Rau B: Hyperthermic intraperitoneal chemotherapy - fading perspective in the light of modern systemic chemotherapy? Visc Med 2018; 34:DOI: 10.1159/000493493.

2 Weber T: Medullary thyroid carcinoma: why is specialization mandatory? Visc Med 2018;34:DOI: $10.1159 / 000493809$.

$\checkmark 3$ Kienle P: Impact of modern drug therapy on surgery: Crohn's disease. Visc Med 2018;34:DOI: $10.1159 / 000495127$.
4 Kuehn F, Hodin RA: Impact of modern drug therapy on surgery: ulcerative colitis. Visc Med 2018;34:DOI: $10.1159 / 000493492$.

5 Alberts C, Alfasser G: Severe acute pancreatitis - how conservative can we be? Visc Med 2018;34:DOI: $10.1159 / 000494097$.

6 D'Haese J, Werner J: Translational research for acute pancreatitis - which results have really influenced our therapy? Visc Med 2018;34:DOI: 10.1159/000493890.
7 Bausch D, Keck T: Minimally invasive surgery of pancreatic cancer: feasibility and rationale. Visc Med 2018; 34:DOI: 10.1159/000495324.

8 Kahn J, Schemmer P: Control of ischemia-reperfusion injury in liver transplantation: potentials for increasing the donor pool. Visc Med 2018;34:DOI: $10.1159 / 000493889$.

9 Otto G: Donor shortage in Germany: impact on shortand long-term results in liver transplantation. Visc Med 2018;34:DOI: 10.1159/000493891.

\section{KARGER}

(๑) 2018 S. Karger GmbH, Freiburg

Fax +497614520714 